\title{
Editorial
}

\section{A responsabilidade da publicação científica}

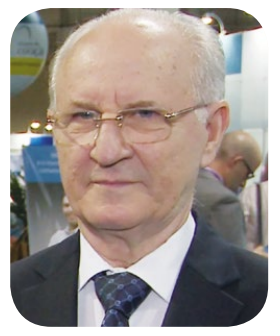

\author{
Gilson Soares Feitosa ${ }^{1}$
}

Este editorial vem como uma homenagem ao Comitê de Ética em Pesquisa Professor Celso Figueiroa, do Hospital Santa Izabel da Santa Casa da Bahia, que por anos tem cumprido um zeloso trabalho, voluntário e quase no anonimato, cuidando entre outras coisas para que nunca, com a chancela do nosso CEP, um desvio de conduta como o observado no relato abaixo, jamais venha a conspurcar a imagem da nossa instituição.

Jornalistas alemães prepararam uma armadilha e forjaram dados inexistentes de uma pesquisa sobre extrato de própolis versus terapia convencional no tratamento de câncer colorretal.

$O$ artigo foi publicado no Journal of Integrative Oncology, periódico em que, sob um preço às vezes elevado, se aceitam trabalhos sem a devida verificação de sua idoneidade.

Por acaso, o jornal é da Índia, pertencente a uma empresa denominada de Omics, e é uma das várias publicações ditas "Open-Access" que se revestem de características falsas de seriedade acadêmica e, como nesse caso, sem a preocupação em inquirir sobre a veracidade dos dados e da origem dos pesquisadores, aceitando a publicação por uns poucos euros.

$\mathrm{Na}$ realidade registram-se várias publicações dessa natureza no mundo atual.

A busca desmesurada pelo ganho financeiro não tem pátria e, nesse caso, em particular, há exemplos na Europa e nos Estados Unidos.

Pacientes não têm acesso direto a essas informações, porém, a comunidade médica, em todos os lugares do mundo, nem sempre tem uma acurada formação científica tem e as consequências deste caso em particular são facilmente deduzidas.

O tratamento estabelecido para o câncer colorretal tem seus reconhecidos efeitos colaterais, sendo à primeira vista atraente a ideia de usar-se extrato de própolis como tratamento preferencial.
Impossível mensurar as consequências disso nessa direção, porém é imaginável que alguém possa ter se iludido com tal premissa.

Não existe ciência sem comunicação.

Está no cerne das atividades científicas investigativas e é o fundamento do crescimento.

Desnecessário dizer-se que há que haver compromisso inquestionável com a veracidade das informações concedidas.

Ao longo do tempo e de modo a garantir aspectos bioéticos de condução da pesquisa médica, tornou-se necessária a criação de CEP independentes e autônomos, que conferem as propostas, seu respeito aos princípios da autonomia do paciente, exige medidas subsequentes de acompanhamento, entre outras medidas, além do nosso caso nacional, de inserção na Plataforma Brasil.

Os periódicos de grande expressão exigem que os trabalhos clínicos, principalmente os de intervenção terapêutica, sejam na fase inicial de sua concepção, já submetidos a organizações de controle e registros de tais ensaios, sendo esse o caso do ReBec-Brazilian Clinical Trials Registry / Registro Brasileiro de Ensaios Clínicos - e do Clinical Trials americano.

Tais exigências dificultam ou impossibilitam a ocorrência de fraudes, como a que se menciona acima.

Por outro lado, vive-se um mundo contemporâneo, de grande competitividade em várias frentes e, entre elas, no mundo das publicações.

Teses são construídas em pós-graduação senso estrito, às vezes com calendários curtos, do que resultam teses não muito expressivas. Mas que são estimuladas a serem publicadas.

A possibilidade de publicá-las nessas revistas de acesso aberto torna-se, em alguns programas, quase que uma necessidade obrigatória para o pós-graduando.

Alertas como esse deverão resultar em um aperfeiçoamento do processo. 


\section{REFERÊNCIAS}

1. Liang F, Zhu J, Mo M, Zhou CM, Jia HX, Xie L, Zheng Y, Zhang S. Role of industry funders in oncology RCTs published in high-impact journals and its association with trial conclusions and time to publication. Ann Oncol. 2018 Aug 2. doi: 10.1093/annonc/mdy305. [Epub ahead of print] PubMed PMID: 30084933.

2. Linker A, Yang A, Roper N, Whitaker E, Korenstein D. Impact of industry collaboration on randomised controlled trials in oncology. Eur J Cancer. 2017 Feb;72:71-77.

3. Van Lent M, Overbeke J, Out HJ. Role of editorial and peer review processes in publication bias: analysis of drug trials submitted to eight medical journals. PLoS One. 2014 Aug 12;9(8):e104846. doi: 10.1371/journal.pone.0104846. eCollection 2014. PubMed PMID: 25118182; PubMed Central PMCID: PMC4130599.

4. Turner L, Shamseer L, Altman DG, Weeks L, Peters J, Kober T, Dias S, Schulz KF, Plint AC, Moher D. Consolidated standards of reporting trials (CONSORT) and the completeness of reporting of randomised controlled trials (RCTs) published in medical journals. Cochrane Database Syst Rev. 2012 Nov 14;11:MR000030. doi: 10.1002/14651858.MR000030. pub2. Review. PubMed PMID: 23152285.

5. Lundh A, Krogsbøll LT, Gøtzsche PC. Sponsors' participation in conduct and reporting of industry trials: a descriptive study. Trials. 2012 Aug 24;13:146.

6. Thorn JC, Noble SM, Hollingworth W. Timely and complete publication of economic evaluations alongside randomized controlled trials. Pharmaco economics. 2013 Jan;31(1):77-85.

1- Editor da Revista Científica do HSI

Endereço para correspondência:

gilson-feitosa@uol.com.br 